\title{
MONITORING TEMPORAL AND SPATIAL CHANGES OF LAND USE AND LAND COVER BASED ON REMOTE SENSING IN THE HILLY REGION OF CENTRAL SICHUAN BETWEEN 1989 AND 2009
}

\author{
Zhen Zeng ${ }^{1}$, Jianrong Fan ${ }^{2 *}$ \\ ${ }^{1}$ Sichuan Geomatics Center, Ministry of Natural Resources of the People' Republic of China \\ ${ }^{2}$ Institute of Mountain Hazards and Environment, Chinese Academy of Sciences \& Ministry of Water Conservancy, Chengdu 610041, \\ China;
}

Commission III, WG III/7

KEY WORDS: Remote sensing, Post-classification comparison, Land use change, Force factor, Lizixi basin

\begin{abstract}
:
In recent years, under the background of government policy and the development of social economy, land use in hilly region of central Sichuan has changed drastically. Especially the Changzhi soil erosion control project that has been carried out since 1989 and the policy of converting from farm land to forest which has been carried out after flooding disaster in 1998, have seriously affected the land use in hilly region of central Sichuan between 1989 and 2009. In order to detect these changes and acquire the land use information, this study was conducted in Lizixi basin which is the typical area in hilly region of central Sichuan. Supervised classification was applied to the processing procedure of TM, SPOT data in 1989, 1999 and Rapideye data in 2009. The results were further improved by visual interpretation. The overall classification accuracy reaches $88.33 \%$ and the kappa is 0.8350 . The elevation was classified into five grades to detect the land use distribution in different elevation gradients in 2009. Post-classification comparisons of the classified images indicated that the major change consists that the cultivated land is decreasing and forest is increasing. The force factor of these changes may be the policy of converting from farmland to forest. Because of the labor shortage, $53.29 \%$ of the decreased cultivated land has changed to abandoned arable land which is covered by lush grass and mainly distribute on the halfway up to the hill. The urban area has enlarged 7 times due to the large number of migrants from rural to urban. Overall these changes reflect the regional policies and human activities are the major and important force factors of changes in the hilly region of central Sichuan during last two decades.
\end{abstract}

\section{INTRODUCTION}

Land is the important resources for human survival and social development(Zezhong Zheng,Dongming Fan et al. 2007). The use of land resources and its cover characteristics can affect not only the sustainable development of social economy, but also indirectly affect the global environment change. Urbanization , industrialization and large scale agricultural activities were the most anthropogenic disturbance to the environment. At the same time, the landscape pattern was the production of the variety of ecological process in the long-term effects on different scales(Sheeja, Joseph et al. 2010, Lubo, Lei et al. 2011). In China, accelerating industrialization and urbanization following high-speed economic development and population increases have greatly impacted land use/cover changes(Lian-Xi, Bo et al. 2004). Several studies have focused on issues related to land use and land cover change (LUCC), and their causes, and eco-environmental impact(Lu, Mausel et al. 2004, Zhong, Huang et al. 2011).

Satellite remote sensing is the most common data source for detection, quantification and mapping of LULC (Land Use and Land Cover) patterns and changes because of its repetitive data acquisition, digital format suitable for computer processing, and accurate georeferencing procedures(Yuan, Sawaya et al. 2005, Abd El-Kawy, Rød et al. 2011) . Remote sensing can truly reflected the surface information and the characters of land use distribution. The multispectral and multi-temporal of the remote sensing data can offer the qualitative and quantitative information for the dynamical detection of land use(Linghai Zhang,Bin Hu et al. 2004). Recently, many researchers prefer using modeling spatial and temporal land use conversion with social-economic data to understanding the causes and consequences of land use changes(Long, Tang et al. 2007). Industrialization, urbanization and population growth have been considered the most common forces contributing to land use change on a global scale(Long, Tang et al. 2007). However, there is no consensus concerning the force factors and change detection to the land use in the hilly region of central Sichuan. Many change detection techniques have been developed, such as post-classification comparison (PCC)(Abd El-Kawy, Rød et al. 2011), image differencing, principle components analysis and vegetation index differencing (Lu, Mausel et al. 2004). The PCC method, which detects land cover change by comparing independently produced classifications of images from different dates, has been recognized as the most accurate change detection technique(Chun Feng, Fang Wu, Rong Liu et al. 2006). Satellite images and socio-economic data are commonly used for quantitatively detecting spatial and temporal dynamics of land use changes based on supervised classification algorithm and post-classification change detection technique in GIS(Dewan and Yamaguchi 2009, Shizhu Jin, Fengzhi Liu. 2011).

The hilly region of central Sichuan is located in the upper and middle basins of the Yangtze River(Jianrong Fan,Zongxin Chai et al. 2001, Fan, Zhang et al. 2004). The land use of this area was complicated. The problem of poor agricultural ecological environment quality and ecological unbalance has always attached great importance by the government and masses. The land use in hilly region of central Sichuan has attracted by many researchers. From 1965-1995, long term observation and 
comparative research were conducted in watershed of Yanting agro-ecological station of purple soil of CAS to analyze land use change and environmental effects. After about 15 years of structure restoration, the agro-forestry model in this region has good ecological, economic and social effects(Bo Zhu, Kui Peng et al. 2001). During 1986 to 1999, the land use of Lizixi basin in hilly region of central Sichuan were also been detected in order to monitor the soil erosion using remote sensing data in this area(Fan, Zhang et al. 2004). But the researches about the land use change detection for nearly 10 years of the hilly region of central Sichuan have been rarely found. In fact as the government's policies and the developments of the society, the land use of this area has changed a lot during the last two decades. In order to detect the land use changes for past two decades and acquire the effects of the Changzhi soil erosion control project, the policy of converting farmland into forest and the migration of population from rural to urban in the hilly region of central Sichuan, this thesis chose the Lizixi basin as the typical study area of the hilly region of central Sichuan to take change detection for last two decades by remote sensing and GIS (Geographic Information System) techniques.

\section{STUDY AREA}

The Lizixi basin locates in the middle part of hilly region of Sichuan, China with latitude and longitude coordinates of $30^{\circ} 22^{\prime}-30^{\circ} 42^{\prime} \mathrm{N}$ and $105^{\circ} 47^{\prime}-106^{\circ} 1^{\prime} \mathrm{E}$ ( Figure 1 ), covers an area of $439 \mathrm{~km}^{2}$ with a north-south of $38 \mathrm{~km}$ and an east-west width of $22 \mathrm{~km}$. The northern part of this area is mainly composed of high hills ( relative height difference $100-200 \mathrm{~m}$ ); the middle part of moderate hills ( relative height difference 50$100 \mathrm{~m} \mathrm{)}$; and the southern part of low hills ( relative height difference $<50 \mathrm{~m}$ ). The altitude varies between $236 \mathrm{~m}$ and $528 \mathrm{~m}$ above sea-level with a maximum height difference of $292 \mathrm{~m}$.

The Lizixi basin has a humid subtropical climate with four distinct seasons. The annual rainfall is $947 \mathrm{~mm}, 90$ percent of which occurs between May and October. Temperature averages $17.5 \mathrm{C}^{\circ}$. The soil in Lizixi basin which are mainly purple soil are the typical of the hilly region in the central Sichuan that are prone to run off and classified as Regosols in the FAO soil taxonomy. Only a small part of vegetation (Cupressus funebris Endl., Pinus massoniana Lamb, Quercus fabri Hance, Quercus glandulifera, Heteropogon contortus,Capillipedium parviflorum, Coriaria sinica Maxim.) are natural, whereas most of vegetation (Oryza sativa L., Triticum aestivum L., Zea mays L., Ipomea batatas Lam., Brassisca campestris L., Glycine max Merr., Citrus reticulata Blanco, Citrus grandis Osbeck., Morus alba L., Aleurites fordii Hemsl., Saccharum sinensis Roxb.) is artificially planted(Fan, Zhang et al. 2004).

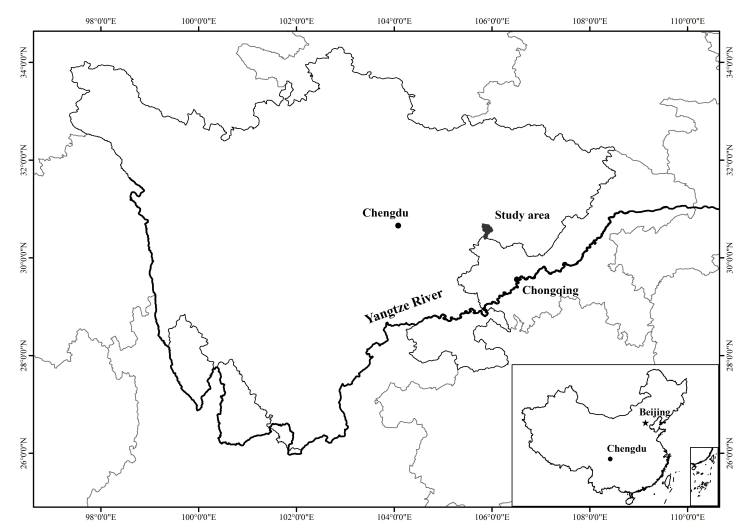

Figure 1 The location of study area

\section{MAIN BODY OF TEXT}

\subsection{Data resources}

The data used in this study includes five images (Table 1), a Thematic Mapper (TM) images fused with SPOT images acquired in 1989,1999 and the Rapideye images acquired on 1 September 2009. All visible and infrared bands (except for the thermal infrared band) were included in the analysis. We digitized topographic maps (scale 1:50000) and use these for geometrically correcting the satellite images.

\begin{tabular}{|l|l|l|l|}
\hline $\begin{array}{l}\text { Satellit } \\
\text { e Type }\end{array}$ & $\begin{array}{l}\text { Ground } \\
\text { Resoluti } \\
\text { on(m) }\end{array}$ & \multicolumn{2}{|l|}{ Band Range(um) } \\
\hline TM & \multirow{3}{*}{30} & Bule band & $0.45-0.52$ \\
& & $\begin{array}{l}\text { Green band } \\
\text { Red band }\end{array}$ & $0.52-0.60$ \\
Near-Infrared band & $0.62-0.69$ \\
SPOT & \multirow{2}{*}{10} & Green band & $0.76-0.96$ \\
& & Red band & $0.61-0.61$ \\
& & Near-Infrared band & $0.78-0.89$ \\
Rapide & 5 & Bule band band & $0.49-0.69$ \\
ye & & Green band & $0.44-0.51$ \\
& & Red band & $0.52-0.59$ \\
Red Edge band & $0.63-0.685$ \\
Near-Infrared band & $0.69-0.73$ \\
& & & $0.76-0.85$ \\
\hline
\end{tabular}

Table 1 Remote sensing data

\subsection{Image pre-processing}

The methodology adopted for this study took into consideration various image pre-processing operations, including atmospheric correction, geometric correction and data fusion. Before the geometrical correction, Rapideye images acquired on 1 September, 2009 are made atmospheric correction by FLAASH model proved by ENVI software(Jianting Hao, Wunian Yang et al. 2008). As the topography is complicated in the hilly region, images must be taken for precise geometric correction. The TM images and SPOT images of 1989 and 1999 were georeferenced by using both control points and topographic maps, and the errors were controlled within 1pixel. The TM images have multispectral information and the SPOT images have higher spatial resolution. In order to make full use of the advantages of both, we fused the TM images and the SPOT images for further study. The 2009 images were geometrically corrected to the 1988 fused images using the error $<1$ pixel. Using ERDAS software the TM data was resampled in $10 \mathrm{~m} \times 10 \mathrm{~m}$ and merged with SPOT data by principal component transformation and bilinear interpolation. With brightness adjustment and contrast enhancement, images which area of both high spatial resolution of SPOT data and rich colors of TM images have been created and can provide more accurate and clear information about the land use in study area.

\subsection{Supervised classification and classification improvement}

We used ERDAS IMAGINE 9.2 software for digital image processing. Training samples were selected for each of the predetermined land use types with the auxiliary of field work in the representative sites. We derived spectral signatures from the 
training samples and entered it into the classification process. The supervised maximum likelihood method was used as a classification method.

Some land use types were spectrally confused and could not be separated well by supervised classification. For instance, the spectral information of dry land is seriously influenced by that of soil background. Because the dry land is left to plough after harvesting corn and other crops, we were always made spectrally confused with paddy land. In addition, the land use spectral information is sheltered from that of lush vegetation (cypress and bamboo) in the north-west part of the study area so that it is difficult for us to extract the true information of land use. For the land use change detection, the land use classification accuracy is particularly important. Supervised classification with the auxiliary of visual interpretation of remote sensing imagery is an effective method for the identification in land use and land cover. Visual interpretation was still a useful method to improve the land use classification of remote sensing imagery (Abd El-Kawy, Rød et al. 2011). We chose visual interpretation method to improve classification accuracy and reduce misclassifications. Finally, we produced accurate land use maps of Lizixi basin.

\subsection{Classification accuracy assessment}

Classification accuracy significantly affects the change detection. It is important to perform accuracy assessment for classification to prove the experimental validation. A classification accuracy assessment was conducted based on 120 random points that were pointed by using a stratified random method in ERDAS software to represent the different land use types of the area. We tested the results of 120 random points against the google earth images which have high spatial resolution and the sample points derived from field work. The overall classification accuracy reaches $88.33 \%$ and the kappa is 0.835 . The results presented the high accuracy because of the help from supervised classification and the visual interpretation which allowed us to correct the misclassified pixels.

\subsection{Detection of land use change}

Post-classification comparison (PCC) was applied to compare and analyze the land use maps in Lizixi basin resulting from the integration of the results of visual interpretation and supervised classification. We use PCC method to detect the changes from each pair of land use maps (i.e. 1989-1999, 1999-2009).

\section{RESULTS AND DISCUSSION}

\subsection{The total area of each land use types for each study year}

The data in the Table 2 presented the results of the land use classification of Lizixi basin by both supervised classification and visual interpretation from remote sensing images which were made accuracy verification. The Fig 2 represents the land use maps in the study area by different time $(1989,1999,2009)$. Fig 3, Fig 4 shows the area of different land use types for different study year. The great change of land use in Lizixi basin has been taken. The cultivated land (including paddy field and dry farm), forest, urban and abandoned arable land have changed a lot between 1989 and 2009. From 1986 to 1999 the area of cultivated land has continuously decreased which was respectively accounted for $93.05 \%, 89.06 \%$ and $63.42 \%$ of the total area in1986. Between 1986 and $1999,3.99 \%$ of the cultivated land has decreased. From 1999 to 2009, the decreased cultivated land has reached to $25.64 \%$. The high ratio of cultivated land decreasing may be the result of the industrialization, urbanization and the government policy, especially after 1998 flood disaster. The area of forest was $15.3 \mathrm{~km}^{2}$ in 1989 and $71.9 \mathrm{~km}^{2}$ in 2009 which had increased more than $12.89 \%$. The reason of the obviously increasing of forest may be the measure of converting cultivated land to forest that the study area has taken and has got great achievement Since 1999. The area of urban in 1989 is $0.76 \mathrm{~km}^{2}$. Until 1999 , the area has increase to $2.68 \mathrm{~km}^{2}$ which was 3.5 times larger than that in 1986. In 2009, the urban expansion is obvious and the area of urban has reached to $5.98 \mathrm{~km}^{2}$ whose area has reached almost 8 times than 1986. The abandoned arable land which is a new kind of deserted farm land has been covered by lush grass. The abandoned arable land was not observed in 1989 and 1999. In 2009, the area of abandoned arable landhas reached to $76.62 \mathrm{~km}^{2}$. As for the river, reservoir, swag and bare land, the changes were not obvious. The result has matched with the existing research result of land use change detection in Lizixi basin since 1986(Yun and Lin).

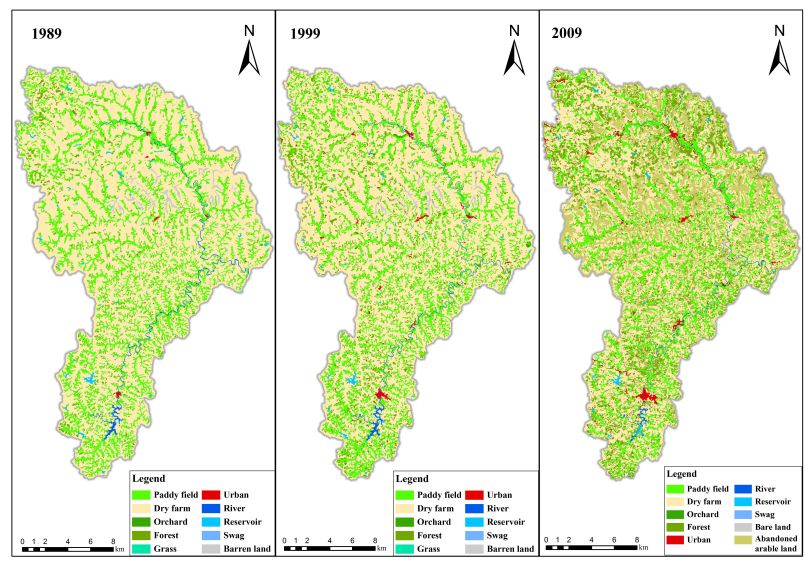

Figure 2 land use maps resulting from the integration of supervised classification and visual interpretation

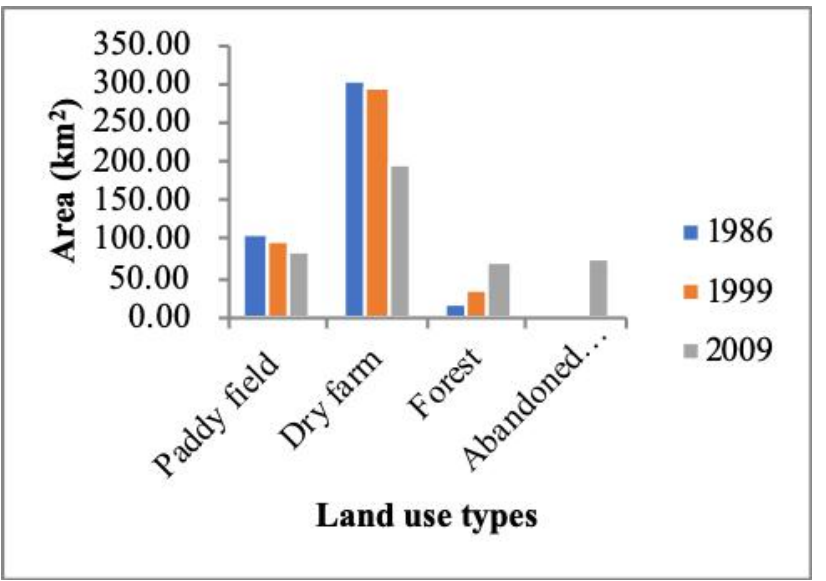

Figure 3 Area of paddy land, dry farm, forest and abandoned arable land for different dates $(1989,1999,2009)$ 


\begin{tabular}{|c|c|c|c|c|c|c|c|}
\hline \multirow{2}{*}{ Land use types } & \multicolumn{2}{|c|}{1989} & \multicolumn{2}{|c|}{1999} & \multirow{2}{*}{ Land use types } & \multicolumn{2}{|c|}{2009} \\
\hline & Area (sq.km) & $\%$ & Area (sq.km) & $\%$ & & Area (sq.km) & $\%$ \\
\hline Paddy field & 106.18 & $24.18 \%$ & 97.75 & $22.26 \%$ & Paddy field & 83.85 & $19.09 \%$ \\
\hline Dry farm & 304.43 & $69.32 \%$ & 293.36 & $66.80 \%$ & Dry farm & 194.65 & $44.32 \%$ \\
\hline Orchard & 0.05 & $0.01 \%$ & 0.36 & $0.08 \%$ & Orchard & 0.08 & $0.02 \%$ \\
\hline Forest & 15.30 & $3.48 \%$ & 35.46 & $8.07 \%$ & Forest & 71.90 & $16.37 \%$ \\
\hline Grass & 1.63 & $0.37 \%$ & 0.43 & $0.10 \%$ & Bare land & 0.12 & $0.03 \%$ \\
\hline Urban & 0.76 & $0.17 \%$ & 2.68 & $0.61 \%$ & Urban & 5.92 & $1.35 \%$ \\
\hline River & 3.89 & $0.89 \%$ & 3.34 & $0.76 \%$ & River & 2.82 & $0.64 \%$ \\
\hline Reservoir & 1.67 & $0.38 \%$ & 1.69 & $0.38 \%$ & Reservoir & 1.71 & $0.39 \%$ \\
\hline Swag & 1.48 & $0.34 \%$ & 1.07 & $0.24 \%$ & Swag & 1.48 & $0.34 \%$ \\
\hline Bare land & 3.75 & $0.86 \%$ & 3.01 & $0.69 \%$ & $\begin{array}{c}\text { abandoned arable } \\
\text { land }\end{array}$ & 76.62 & $17.45 \%$ \\
\hline Total & 439.16 & & & & & & \\
\hline
\end{tabular}

Table 2 Results of land use / land cover classification for 1989, 1999 and 2009 images. Showing the study area of each category and class percentage

\begin{tabular}{|c|c|c|c|c|c|}
\hline From Class & To Class & $1989-1999(\mathrm{sq} . \mathrm{km})$ & $\%$ & $1999-2009(\mathrm{sq} . \mathrm{km})$ & $\%$ \\
\hline \multirow{2}{*}{ Cultivated land } & Forest & 25.40 & $86.83 \%$ & 55.21 & $41.69 \%$ \\
& Abandoned arable land & - & - & 70.57 & $53.29 \%$ \\
\hline
\end{tabular}

Table 3 The cultivated land conversions 1989-1999 and 1999-2009

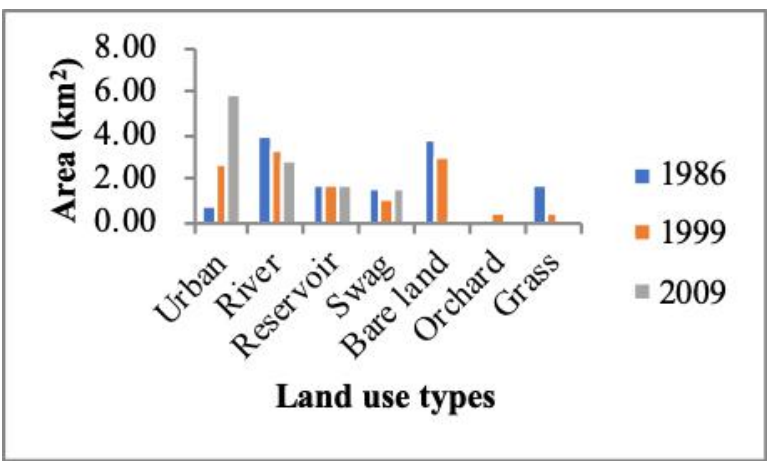

Figure 4 Area of urban, river, reservoir, swag, bare land, orchard and grass for different dates $(1989,1999,2009)$

\subsection{The change and distribution of the conversion from cultivated land to forest for 1989-1999 and 1999-2009}

In 1989, Lizixi basin which belongs to the hilly region of centre Sichuan was the major agricultural region of Sichuan province. The cultivated land (including the paddy field and the dry farm) were $410.61 \mathrm{~km}^{2}$ which occupied approximately $93.5 \%$ of the study area (Table 2). Until 1999, the cultivated land had decreased to $391.11 \mathrm{~km}^{2}$ which accounted for $89.06 \%$ of the total area of Lizixi basin. In 2009, the cultivated land has decreased significantly which has just accounted for $63.42 \%$. At the same time, the forest has occupied respectively $3.48 \%$, $8.07 \%$ and $16.37 \%$ of the total study area in 1989,1999 and 2009 (Fig 3). Between 1989 and 1999, 25.4km² of cultivated land converted into forest which accounted for $86.83 \%$ of the decreased area of cultivated land (Table 3). Large percent of decreased cultivated land converted into forest is likely to be a result of the Changzhi soil erosion control project carried out between 1989 and 1999 in the hilly region of central Sichuan. In order to improve the ecological environment and reduce the soil erosion of hilly region of central Sichuan, the Changzhi soil erosion control project has been taken and has achieved results.
Especially after the flooding disaster in 1998, the government and masses have paid more attention to ecological environment. So from 1999 to $2009,41.69 \%$ of the decreased cultivated land had been converted into forest. This marked change may result from the policy of the converting farmland into forest which started from 1999 in the study area and has got obvious achievements. The policy of the converting farmland into forest also impacted the decrease of cultivated land and the increase of forest. The increased forest distributed in the north-west and south-west of the Lizixi basin (Fig 5). The increasing of forest between 1999 and 2009 is more obvious than that between 1989 and 1999. The continual policy of converting farmland into forest has achieved great results.
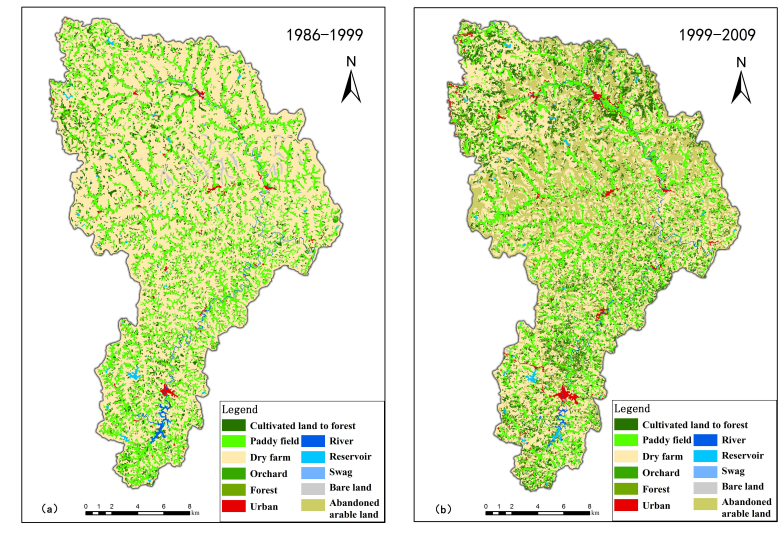

Figure 5 Geospatial distributions of conversions from cultivated land to forest in different study year 
4.3 The change and distribution of the conversion from cultivated land to abandoned arable land for 1989-1999 and 1999-2009

At the bottom of the hill, there are mainly covered by cultivated land. At the middle of the hill, there covered by forest which are converted from the farm land. Halfway up to the hill, large area of cultivated land converted into abandoned arable land which has been covered by lush grass (Fig 6). The abandoned arable land is a new kind of deserted land which was cultivated land before the labor force has decreased. Because of the lack of farming and management, the past-cultivated land has turned into the abandoned arable land which has been covered by lush grass.

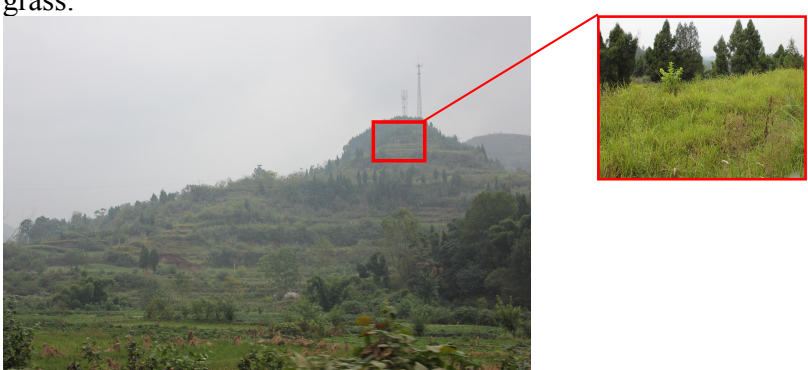

Figure 6 Geospatial distributions of conversions from cultivated land to forest in different study year
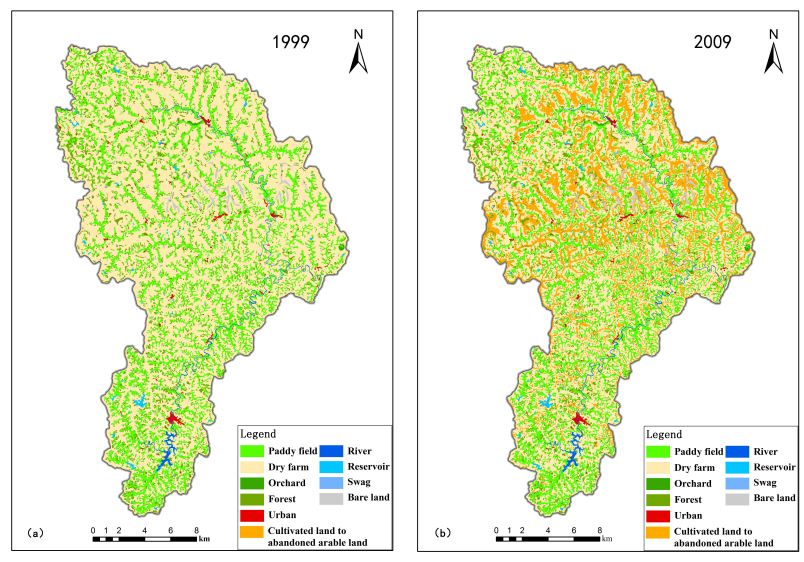

Figure 7 Geospatial distributions of conversions from cultivated land to abandoned arable land in different study year

As the social and economic development, a lot of rural residents work in the city. In the rural, there are only left-behind children and the elderly left. The left-behind children and the elderly are both the vulnerable groups. The limitation of the labor force has been the major reason for the increasing of the abandoned arable land. The abandoned arable land was not observed before 1999. Between 1999 and 2009, 70.57 $\mathrm{km}^{2}$ of cultivated land converted into abandoned arable land which occupied 53.29\% of the total decreased cultivated land (Table 3). To 2009, the area of the abandoned arable land has reached to $76.62 \mathrm{~km}^{2}$ which accounted for $17.45 \%$ of the total study area. Because of the long time uncultivated, the abandoned arable land has been covered by lush grass. The distribution of the abandoned arable land where is not convenient to access to and the halfway up the hill is more obvious and serious. As to the point of the view of space, large area of cultivated land distributed at the middle of Lizixi basin has converted into abandoned arable land (Fig 7). As the development of society, more and more young labour force deserted the cultivated land and the area of abandoned arable land will be larger. The government should pay more attention to this phenomenon. Some measures must be taken to control the decrease of the cultivated land and the increase of the abandoned arable land and take full use of the land.

\subsection{The urban expansion for 1989-1999 and 1999-2009}

Between 1989 and 2009, the urban expansion is obvious. Compared to 1989 , the area of urban has reached $2.68 \mathrm{~km}^{2}$ which is more than 3 times larger in 1999. In 2009, the area of urban was $5.92 \mathrm{~km}^{2}$ that is more than 7 times larger than in 1989 . For example, the Figure 8 showed one of the urban expansions from 1989 to 2009 . The annual rate of change in urban class was $0.04 \%$ and $0.07 \%$ for the periods $1989-1999$ and 1999 2009. The social and economic development and the contribution of the continually increasing of population may be the reason of the urban expansion (Figure 8 shows the urban expansion). With the continuous development of social economy, urban expansion is also accelerating. All these physical changes reflect the dynamics of human impacts on the study area.
1986

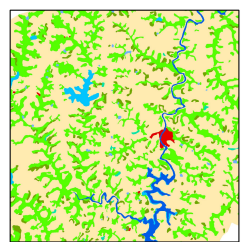

1999

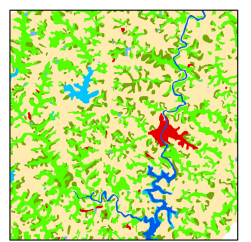

Paddy field Dry far

River
2009

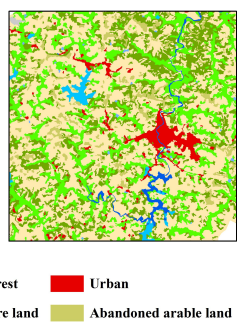

Figure 8 The expansion of the urban area for different study year

\subsection{The land use distribution of Lizixi basin in 2009}

Different land use types in hilly region of central Sichuan distributed in different elevation gradients (Figure 9). In order to detect altitude distribution characters in this regions, the elevation in typical study area were classified into 5 grades that included lower than $300 \mathrm{~m}, 300 \mathrm{~m}-350 \mathrm{~m}, 350 \mathrm{~m}-400 \mathrm{~m}, 400 \mathrm{~m}$ $500 \mathrm{~m}$ and higher than $500 \mathrm{~m} .85 .53 \%$ of the paddy land distributed in the region of lower than $350 \mathrm{~m}$ where is close to the water. The dry farm which is mainly comprise of slope cropland in Lizixi basin distributed on the hillside during different altitude. The hilly region of central Sichuan has high vegetation coverage. The forest mainly distributed on the hillside from $300 \mathrm{~m}-500 \mathrm{~m}$. The urban city either distributed lower than $300 \mathrm{~m}$ or higher than $500 \mathrm{~m}$ which avoided distributing on the hillside to settle in the gently region. As the high altitude region is inconvenient to access to and the decrease of labor force, the abandoned arable land is mainly scattered in the region of higher than $300 \mathrm{~m}$ which accounted for $96.9 \%$ of the total abandoned arable land. 


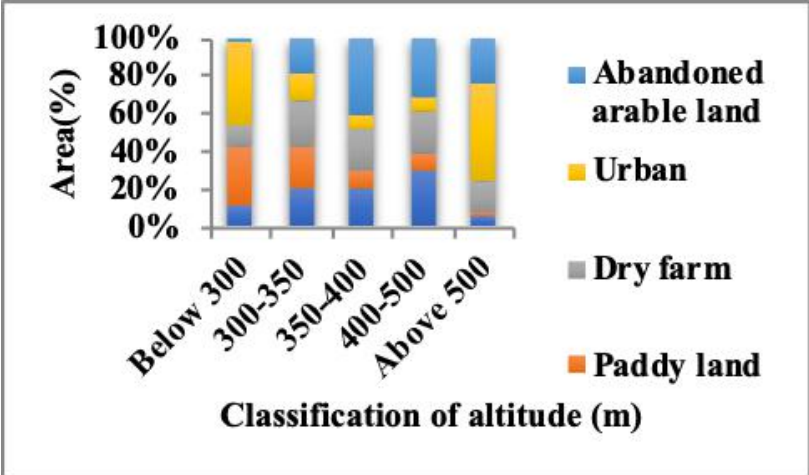

Figure 9 The distribution of forest, paddy field, dry farm, urban and abandoned arable land in different elevation gradients

\section{CONCLUSION}

The great change has been taken in the hilly region of central Sichuan for last two decades. The Changzhi soil erion control project and the policy of converting farmland into forest that has taken place during the last decade has obviously affected the land use change of the hilly region of central Sichuan. Especially in the northwest and southwest parts of the Lizixi basin, the forest has increase obviously. The increased forest has occupied almost half of the decreased cultivated land. The government has paid more and more attention to the ecological environment. The government policy and human impacts have obviously affected the land use in the hilly region.

As the social and economic development, there are more and more migrants from rural area to the urban. The decreasing of rural population directly results in the extremely lack of rural labour force which led to large area of cultivated land converting into abandoned arable land. What's more, the migrants from rural area to the urban are also the major force for the urban expansion. During the last two decades, the land use and land cover of hilly region of central Sichuan has changed a lot. The level of area change of different land use is cultivated land $>$ forest $>$ urban city. These changes reflect the regional policies and the dynamics of human impacts are the major and important force factor for the obvious land use changes in the hilly region of central Sichuan during last two decades.

In 1989, the hilly region of central Sichuan is the major agricultural region of Sichuan province. But now, the cultivated land has decreased seriously. The high percentage of cultivated land converted into abandoned arable land not only results in the decrease of grain yield, but also can obviously affect the water and soil loss in hilly region of central Sichuan. Considering the undesirable changes in land use and the need for more sustainable development in the region, we suggest that the government should consider the policies to the study region and the surrounding regions which may directly or indirectly affect the study region to balance the contradictions not only between the grain yield and ecological construction, but also between the ecological construction and social economy.

Next, we will continue making classification of Lizixi district based on remote sensing images in 2019. Then we can detect the landuse change in thirty years.

\section{ACKNOWLEDGEMENT}

The authors would like to thank P.Cheng and F.Q.Dai for their great help in polishing language.

\section{REFERENCES}

Abd El-Kawy O R, Rød J K, Ismail H A et al., 2011. Land use and land cover change detection in the western Nile delta of Egypt using remote sensing data. Applied Geography, 31(2): 483-494.

Dewan A M, Yamaguchi Y, 2009. Land use and land cover change in Greater Dhaka, Bangladesh: Using remote sensing to promote sustainable urbanization. Applied Geography, 29(3): $390-401$.

Fan J R, Zhang J H, Zhong X H et al., 2004. Monitoring of soil erosion and assessment for contribution of sediments to rivers in a typical watershed of the Upper Yangtze River Basin. Land Degradation \& Development, 15(4): 411-421.

Wu L X, Sun B, Zhou S L et al., 2004. A New Fusion Technique of Remote Sensing Images for Land Use/Cover. Pedosphere, 14(2): 187-194.

Long H, Tang G P, Li X B et al., 2007. Socio-economic driving forces of land-use change in Kunshan, the Yangtze River Delta economic area of China. Journal of Environmental Management, 83(3): 351-364.

Lu D, Mausel P, Brondízio E et al., 2004. Change detection techniques. International Journal of Remote Sensing, 25(12): 2365-2401.

Gao L B, Yun L, Ren Y et al., 2011. Spatial and Temporal Change of Landscape Pattern in the Hilly-Gully Region of Loess Plateau. Procedia Environmental Sciences, 8: 103-111.

Mas J F, 1999. Monitoring land-cover changes: A comparison of change detection techniques. International Journal of Remote Sensing, 20(1): 139-152.

Sheeja R V, Joseph S, Jaya D S et al., 2010. Land use and land cover changes over a century (1914-2007) in the Neyyar River Basin, Kerala: a remote sensing and GIS approach. International Journal of Digital Earth, 4(3): 258-270.

Singh A, 1989. Review Article Digital change detection techniques using remotely-sensed data. International Journal of Remote Sensing, 10(6): 989-1003.

Yuan F, Sawaya K E, Loeffelholz B C et al., 2005. Land cover classification and change analysis of the Twin Cities (Minnesota) Metropolitan Area by multitemporal Landsat remote sensing. Remote Sensing of Environment, 98(2-3): 317-328.

Yun, Z. and W. Lin LUCC and Its Impact on Run-Off and Sediment Yields in the Lizixi Watershed. Civil Engineering and Urban Planning 2012: 356-361.

Zhong T Y, Huang X J, Zhang X Y et al., 2011. Temporal and spatial variability of agricultural land loss in relation to policy and accessibility in a low hilly region of southeast China. Lnd Use Policy, 28(4): 762-769. 
Fan J R, Chai Z X, Liu S Z et al., 2001. Dynamical changes of soil erosion in Lizixi catchment of Sichuan province by remote sensing and geographical information system. Jouranl of Soil and Water Conservation, 15(4): 25-28. (in Chinese)

Feng C, Guo J Y, Min X J et al., 2006. New progress in land use/ land cover change detection by remote sensing. Remote Sensing Information, (3): 81-85. (in Chinese)

Hao J T, Yang W N, Li Y X et al., 2008 Atmospheric correction of muti-spectral imagery ASTER. Remote Sensing Information, (1): 78-81. (in Chinese)

Jin S Z, Liu Z F, 2011. Dynamic change of land use in Yanji City based on TM images. Scientia Geographica Sinica, 31(10): 1249-1253. (in Chinese)

Liu J B, 2011. Analysis land use dynamic change based on ENVI. Journal of Anhui Agricultural Science, 39(8): 4784-4786. (in Chinese)

Wu F, Liu R, Tian W C et al., 2007. Technology of remote sensing change detection and its application. Geospatial Information, 26(4): 57-60. (in Chinese)

Zhang H L, Hu B, Yin J F, 2004. Application of remote sensing and GIS in dynamic monitoring of land use. Image Technology, (2): 43-46. (in Chinese)

Zheng Z Z, Fan D M, Yang W N et al., 2007. Dynamic monitoring of land use changes based on interation of RS, GIS and GPS. Journal of Southwest Jiaotong University, 42(4): 409413. (in Chinese)

Zhu B, Peng K, Gao M R et al., 2001. Land use changes and effects on eco-environment in hilly area of central Sichuan basin. Journal of Mountain Science, 19: 14-19. (in Chinese) 